\title{
KDNBF 形貌控制及其对热分解行为和感度的影响
}

\author{
冯金玲 ${ }^{1}$ 张建国 ${ }^{1, *}$ 张同来 ${ }^{1, *}$ 李志敏 ${ }^{1}$ 杨 利 ${ }^{1}$ 王绍宗 ${ }^{2}$ \\ ( ${ }^{1}$ 北京理工大学爆炸科学与技术国家重点实验室, 北京 $100081 ;{ }^{2}$ 机械科学技术研究院, 北京 100083)
}

\begin{abstract}
摘要：通过 7-差基-4,6-二硝基-5,7-二氢苯并呋咱(DNBF)的钠盐与硫酸钾在水溶液中反应,制备得到 DNBF 的 钾盐(KDNBF). 在制备过程中加人不同表面活性剂, 得到了不同晶形的 KDNBF 样品. 运用 X 射线粉末衍射 分析了单种晶形控制剂对样品晶形的影响. 采用差示扫描量热(DSC)和热重(TG)分析技术研究了不同晶形样品 的热分解特性, 利用 Kissinger 方法和 Ozawa-Doyle 方法研究了样品第一放热分解峰的分解动力学过程. 结果表 明球形样品与其它晶形的样品相比, 具有较低的分解温度、较高的活化能; 同时发现, 球形样品具有较高的摩擦 和撞击感度与较低的火焰感度.
\end{abstract}

关键词：热行为； 7-羟基-4,6-二硝基-5,7-二氢苯并呋咱钾； 晶形； 感度； 表面活性剂 中图分类号：0642；0643；0647

\section{Morphology Control and Its Influence on the Decomposition Behavior and Sensitivity of KDNBF}

\author{
FENG Jin-Ling ${ }^{1}$ \\ ZHANG Jian-Guo ${ }^{1,}$ \\ ZHANG Tong-Lai ${ }^{1, *}$ \\ LI Zhi-Min ${ }^{1}$ \\ YANG $\mathrm{Li}^{1} \quad$ WANG Shao-Zong ${ }^{2}$ \\ ('State Key Laboratory of Explosion Science and Technology, Beijing Institute of Technology, Beijing 100081, P. R. China; \\ ${ }^{2}$ Academy of Machinery Science \& Technology, Beijing 100083, P. R. China)
}

\begin{abstract}
The potassium salt of 7-hydroxy-4,6-dinitro-5,7-dihydrobenzofuroxanide (KDNBF) was prepared by a reaction of the sodium salt of DNBF with potassium sulfate in aqueous solution. Samples of KDNBF with different morphologies were obtained by adding various surfactants. The effect of a single surfactant on the sample morphology was determined with powder X-ray diffraction (XRD) data. The thermal decomposition behaviors of KDNBF with different shapes were studied using differential scanning calorimetry(DSC) and thermogravimetry (TG) analyses. The kinetic parameters of the exothermic processes were studied by applying the Kissinger's and Ozawa-Doyle's methods. The results show that the spherical sample has a lower decomposition temperature and higher reaction activation energy than the other forms of the sample. Furthermore, impact sensitivity, flame sensitivity, and friction sensitivity tests indicated that the spherical KDNBF sample has stronger friction and impact sensitivities and weaker flame sensitivity.
\end{abstract}

Key Words : Thermal behavior; Potassium salt of 7-hydroxy-4,6-dinitro-5,7-dihydrobenzo-furoxanide; Morphology; Sensitivity; Surfactant

Energetic materials containing potassium have attracted more and more attention because of their merits of no heavy metal pollution to environment and appropriate sensitivity properties ${ }^{[1-5]}$.
The potassium salt of 7-hydroxy-4,6-dinitro-5,7-ihydrobenzofuroxanide $(\mathrm{KDNBF})$ is more stable and less impact sensitive than the parent compound, therefore it has been used in primary

Received: May 12, 2010; Revised: June 22, 2010; Published on Web: August 25, 2010.

${ }^{*}$ Corresponding authors. ZHANG Jian-Guo, Email: zhangjianguobit@yahoo.com.cn; Tel/Fax: +86-10-68913818.

ZHANG Tong-Lai, Email: ztlbit@bit.edu.cn.

The project was supported by the National Natural Science Foundation of China (20471008) and Program for New Century Excellent Talents in Universities of the Ministry of Education of China (NCET-09-0051).

国家自然科学基金(20471008)和教育部新世纪优秀人才支持计划(NCET-09-0051)资助项目

(C) Editorial office of Acta Physico-Chimica Sinica 
explosive and initiator compositions since the early 1950s. Many researches on KDNBF were reported ${ }^{[6-16]}$, but most of them are focus on the application and thermal properties, only a few about the morphological property ${ }^{[17-18]}$.

Morphological property of energetic material has a great influence on thermal stability and energetic properties, especially the density and free-flowing property ${ }^{[19]}$. Hence, it is very important to regulate the crystallization in the process of synthesis. Adding different surfactants into the reaction system is a common and useful method to obtain the ideal crystal. McGuchan ${ }^{[20]}$ has done a lot of investigations on the regulation of crystal morphology of KDNBF, and gained the granular KDNBF. Other researchers $^{[21-22]}$ have also studied on this aspect, but got unideal results. Therefore, further research should be carried out on the morphology of KDNBF and the influence related to different morphologies.

Enlightened by the previous studies, herein we report on the regulation of KDNBF with different morphologies by adding specific surfactants in the process of reaction. Thermal decomposition behavior and sensitivity of the various shapes have been studied in detail.

\section{Experimental}

\subsection{Materials and instruments}

KDNBF was synthesized based on the method reported in Ref.[23]. Other chemical reagents and solvents (analytical grade) were used as supplied if not stated otherwise.

The shapes of the samples were examined by XTL-500 Stereo Microscopes from Guilin Optical Instrument Factory (China), using the trinocular body with the square post and integrated transmitted and reflected illumination. The working distance is $26 \mathrm{~mm}$, and the magnification is $32.5 \times-225 \times$ (Eyepiece WF25 $\times$, Objective zoom range $0.65 \times-4.5 \times$, auxiliary Objective $2 \times$ ). The experimental magnification we used is $32.5 \times$. Powder XRD analyses were determined by Rigaku D/Max-2500 Diffractometer (Japan). The scanning range and the scanning speed are $3^{\circ}-$ $80^{\circ}$ and $8\left(^{\circ}\right) \cdot \mathrm{min}^{-1}$, respectively. The differential scanning calorimeter (DSC) and thermogravimetry(TG) were carried out on Perkin-Elmer Pyris-1 (USA) dif- ferential scanning calorimeter and thermo-gravimetric analyzer, respectively, using dry oxygen-free nitrogen as atmosphere with the flowing rate of $20 \mathrm{~mL}$. $\mathrm{min}^{-1}$. The sample of about $0.5 \mathrm{mg}$ was sealed in aluminum pans for DSC with a various heating rate $\left(2,5,10,20{ }^{\circ} \mathrm{C} \cdot \mathrm{min}^{-1}\right)$ from 50 to $600{ }^{\circ} \mathrm{C}$, and was held in plat- inum pans for TG with a heating rate of $10{ }^{\circ} \mathrm{C} \cdot \mathrm{min}^{-1}$.

\subsection{Preparation}

The synthesis route of KDNBF is shown in Scheme 1. DNBF (4.52 g, $0.02 \mathrm{~mol}$ ) was added to $120 \mathrm{~mL}$ distilled water with stirring, the suspending solution obtained was heated to $60{ }^{\circ} \mathrm{C}$. $\mathrm{NaHCO}_{3}(1.76 \mathrm{~g}, 0.025 \mathrm{~mol})$ was added gradually with continuous stirring. Keep the mixtures reacting for $20 \mathrm{~min}$ with stirring, then cool to room temperature. Regulate the value of $\mathrm{pH}$ of the mixture to 5.5. Filtrate the precipitation and the red-brown solution of NaDNBF was obtained after a few minutes.

The solution of NaDNBF was transferred to a cylinder beaker at $37{ }^{\circ} \mathrm{C}$. Then specific surfactant was added into the solution. After stirring for $10 \mathrm{~min}$, solution of $\mathrm{K}_{2} \mathrm{SO}_{4}(2 \mathrm{~g}, 0.015 \mathrm{~mol})$ dissolved in $30 \mathrm{~mL}$ distilled water was dripped slowly during 20 min. After another $10 \mathrm{~min}$ reaction, the mixture was cooled to room temperature with cold water bath. The precipitate was filtered and washed twice with distilled water and once with ethanol $(30 \mathrm{~mL})$. Different shapes of KDNBF obtained were shown in Fig.1.

\section{Results and discussion}

\subsection{Morphology of KDNBF with different surfactants}

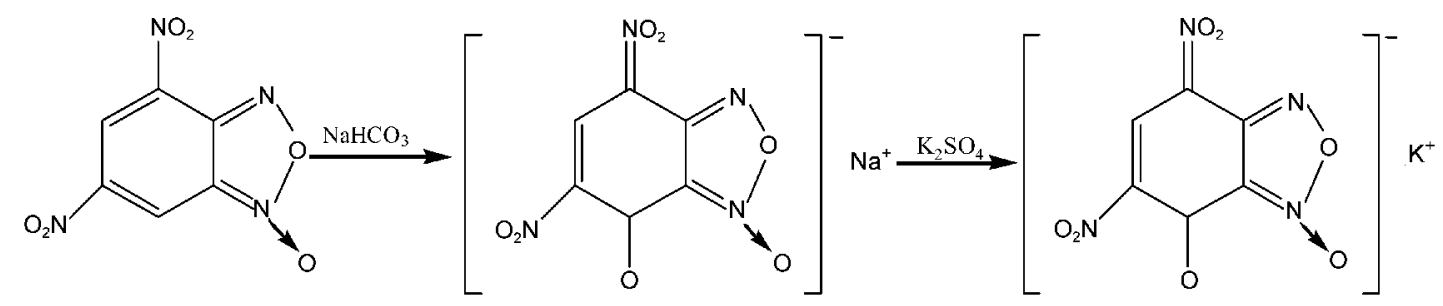

Scheme 1 The route of preparation of KDNBF
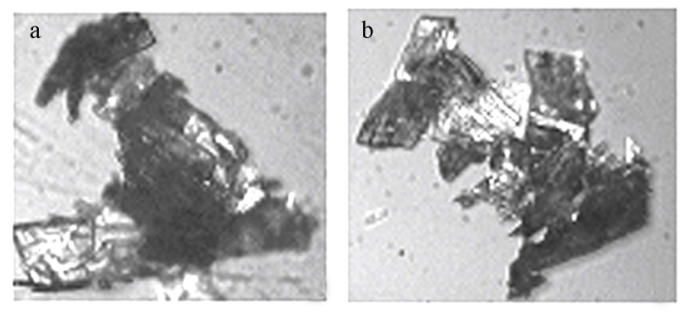
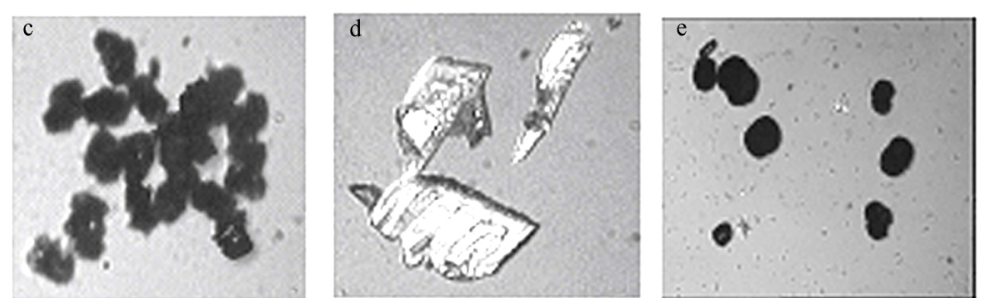

Fig.1 Morphologies of KDNBF with different surfactants

(a) the sample without surfactant, (b) the sample with surfactant PAM, (c) the sample with surfactant PVA, (d) the sample with surfactant Tween20, (e) the sample with the mixed surfactant: $8 \mathrm{~mL}$ PAM $(0.05 \%, w), 10 \mathrm{~mL} \mathrm{PVA}(2 \%)$, and $11 \mathrm{~mL}$ Tween $20(0.5 \%)$ 
From Fig.1 we can see different morphological properties of KDNBF caused by adding various surfactants into the reaction system. The morphologies of the sample in Fig.1a, Fig.1b, and Fig.1d are all sheet, but the former two have more edges and corners than that in Fig.1d. The morphologies of the sample in Fig.1c and Fig.1e are both spherical, but the latter one is more regular than that in Fig.1c. The results reveal that the surfactants PAM and Tween 20 have similar influence on the crystallization of the sample, and the surfactant PVA plays an important role in the mixed surfactant to make the crystal spherical. The influence of surfactant on the morphology was affected by the adsorption of different surfactants in the different crystalline plates. With a various rate of growing along each crystalline plate, the crystal will has different morphologies. All of the above results indicate that the surfactant has an obvious influence on the morphology of KDNBF.

\subsection{Powder XRD analyses of KDNBF with different morphologies}

The effect of single surfactant on the sample morphology was determined with XRD data (Fig.2). As we can see from Fig.2, the main diffraction peaks occur at similar diffraction angles, however, the diffraction intensities are different. When the sample is sheet, the highest diffraction peak appears at about $2 \theta=19.92^{\circ}$, which is generated by $(\overline{3} 11)$ crystal face; when the sample is spherical, the highest diffraction peak is generated by $(\overline{4} 03)$ face, with the $2 \theta$ value being $29.12^{\circ}$.

The percent of each crystal face $(\% h k l)$ in the crystal growth process can be calculated by the following formula:

$$
\% h k l=\frac{I_{h k l} / I_{h k l}^{*}}{\sum_{h k l}\left(I_{h k l} / I_{h k l}^{*}\right)} \times 100 \%
$$

where $I_{h k l}^{*}$ is relative intensity of XRD peak of pure sample; $I$ is relative intensity of XRD peak of different samples with varied condition.

The values of $\% h k l$ of KDNBF with different morphologies are listed in Table 1. When the surfactant is PAM, the dominant

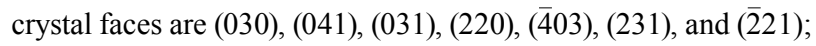
when the surfactant is PVA, the dominant crystal faces are ( $\overline{4} 03),(220),(231)$, and (221); when the surfactant is Tween20, the dominant crystal faces are (231), (403), (220), (031), and (221); when we used mixed surfactant, the dominant crystal

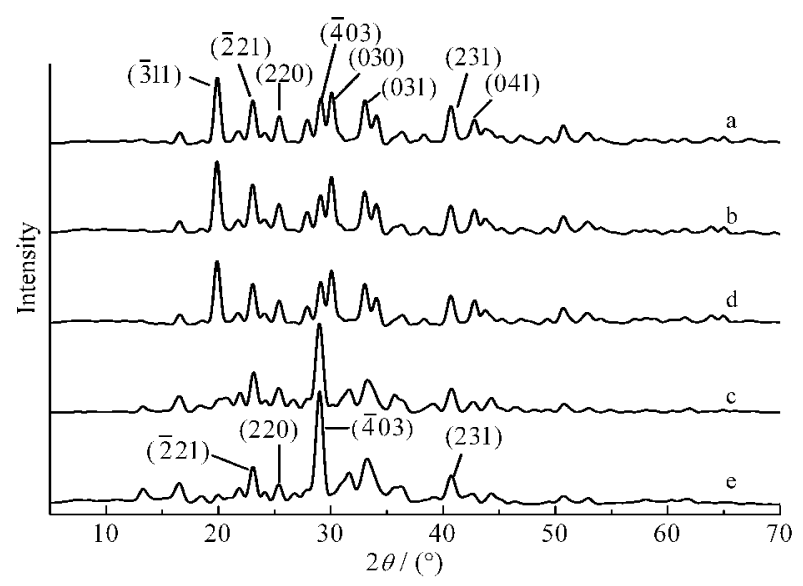

Fig.2 Powder XRD patterns of KDNBF with different surfactants

The meanings of a-e are the same as those in Fig.l

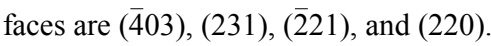

In conclusion, when the morphology of sample is different, the diffraction angle of the highest peak and the corresponding

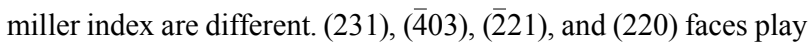
important roles during the crystal growth of KDNBF-surfactant, the percent of the effect changed according to the kind of surfactant. When the sample is sheet, crystal faces (030), (041), and (031) also affect the crystal growth process.

\subsection{Decomposition behavior of KDNBF with different morphologies}

Fig. 3 shows the DSC curves of KDNBF with different morphologies at various heating rates. The peak temperatures of each DSC curve of KDNBF with different surfactants at various heating rates are shown in Table 2.

From the DSC curves in Fig. 3 and the data in Table 2, we can see that the sample with different morphologies has different decomposition temperatures at the same heating rate. As shown in Fig.3B, the heating rate is $5{ }^{\circ} \mathrm{C} \cdot \mathrm{min}^{-1}$, the peak temperature $\left(T_{\mathrm{p}}\right)$ in the process of decomposition of the sample with mixed surfactant is $208.10{ }^{\circ} \mathrm{C}, T_{\mathrm{p}}$ of the sample with surfactant PVA is a few higher than that of the mixed surfactant with the value of $212.28{ }^{\circ} \mathrm{C}$, the other three have the approximate values of 216.78, 216.50, and $216.98{ }^{\circ} \mathrm{C}$, respectively. Meanwhile, we obtained the same conclusion according to the results of the other

\begin{tabular}{|c|c|c|c|c|c|c|c|c|c|}
\hline \multirow{2}{*}{$h k l$} & \multirow{2}{*}{$I^{*}$} & \multicolumn{2}{|c|}{ PAM } & \multicolumn{2}{|c|}{ PVA } & \multicolumn{2}{|c|}{ Tween 20} & \multicolumn{2}{|c|}{ Mixed surfactant } \\
\hline & & $I$ & $\% h k l$ & $I$ & $\% h k l$ & $I$ & $\% h k l$ & $I$ & $\% h k l$ \\
\hline$(\overline{3} 11)$ & 100.0 & 4631 & 9.68 & 983 & 3.92 & 5170 & 9.68 & 663 & 2.24 \\
\hline$(\overline{2} 21)$ & 52.8 & 2683 & 10.62 & 1837 & 13.88 & 3095 & 10.98 & 2093 & 13.37 \\
\hline (220) & 33.2 & 1766 & 11.12 & 1371 & 16.47 & 2028 & 11.44 & 1087 & 11.05 \\
\hline$(\overline{4} 03)$ & 45.0 & 2741 & 11.05 & 2674 & 23.70 & 3096 & 12.88 & 4486 & 33.63 \\
\hline (030) & 78.7 & 4075 & 12.74 & 771 & 3.91 & 4051 & 9.64 & 486 & 2.08 \\
\hline (031) & 44.4 & 2412 & 11.36 & 1129 & 10.14 & 2630 & 11.09 & 1298 & 9.86 \\
\hline (230) & 37.1 & 1895 & 10.68 & 985 & 10.59 & 2105 & 10.62 & 826 & 7.51 \\
\hline (231) & 21.0 & 1096 & 10.91 & 744 & 14.13 & 1513 & 13.49 & 934 & 15.01 \\
\hline (041) & 24.2 & 1397 & 12.07 & 198 & 3.26 & 1315 & 10.18 & 376 & 5.24 \\
\hline
\end{tabular}

Table 1 Values of $\% h k l$ of KDNBF with different morphologies 

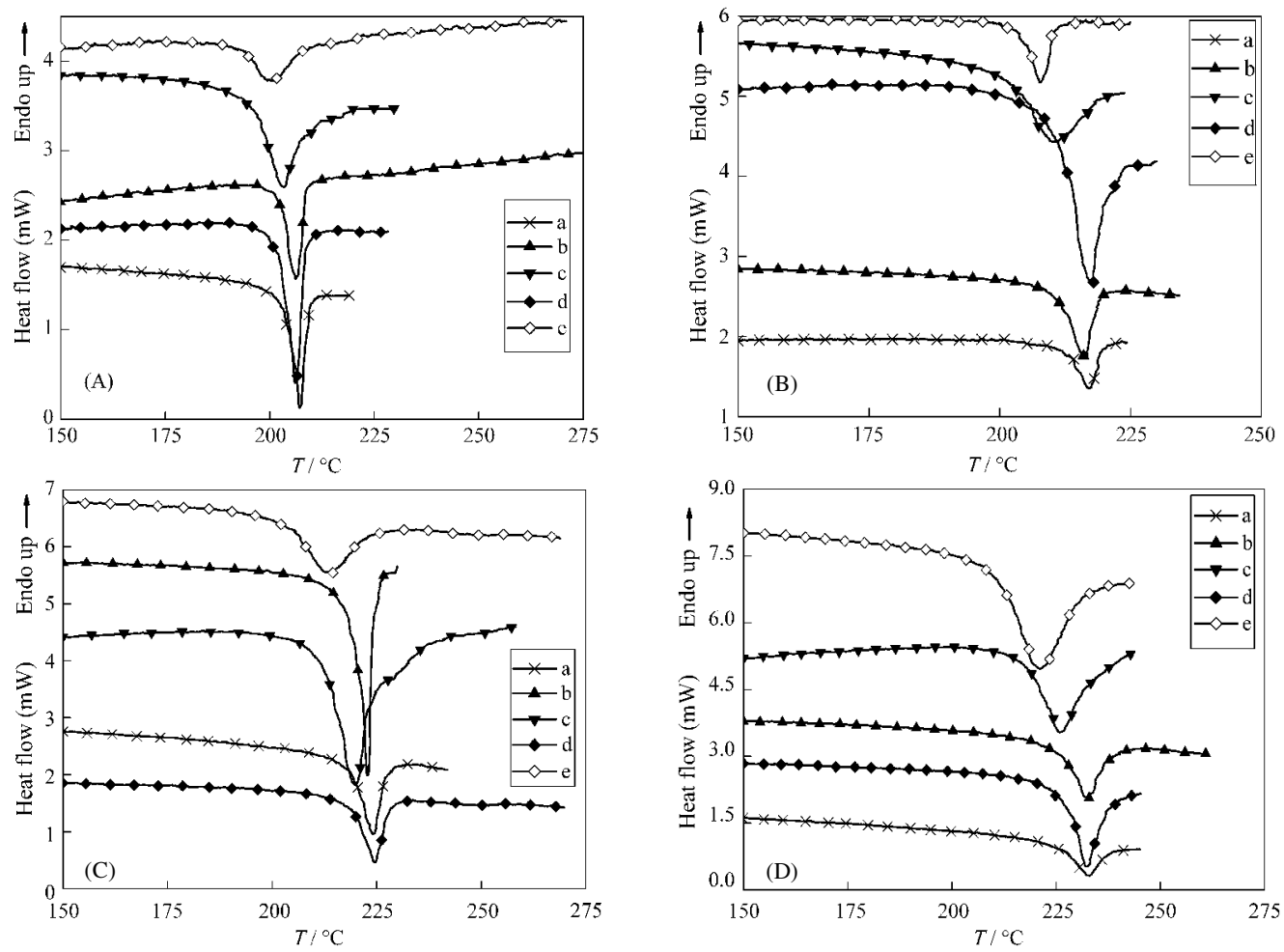

Fig.3 DSC curves of KDNBF with different surfactants

heating rate $\left({ }^{\circ} \mathrm{C} \cdot \mathrm{min}^{-1}\right)$ : (A) 2, (B) 5 , (C) 10, (D) 20; The meanings of a-e are the same as those in Fig.1.

Table 2 Peak temperatures $\left(T_{\mathrm{p}}\right)$ of DSC curves of KDNBF with different surfactants at varied heating rates

\begin{tabular}{ccccc}
\hline \multirow{2}{*}{ Sample } & \multicolumn{4}{c}{$T_{\mathrm{p}} /{ }^{\circ} \mathrm{C}$} \\
\cline { 2 - 5 } & $2{ }^{\circ} \mathrm{C} \cdot \mathrm{min}^{-1}$ & $5{ }^{\circ} \mathrm{C} \cdot \mathrm{min}^{-1}$ & $10{ }^{\circ} \mathrm{C} \cdot \mathrm{min}^{-1}$ & $20{ }^{\circ} \mathrm{C} \cdot \mathrm{min}^{-1}$ \\
\hline a & 206.93 & 216.78 & 224.10 & 232.82 \\
b & 206.88 & 216.50 & 223.67 & 233.50 \\
c & 203.45 & 212.28 & 219.36 & 225.76 \\
d & 206.50 & 216.98 & 224.75 & 230.97 \\
e & 200.56 & 208.10 & 215.17 & 222.86 \\
\hline
\end{tabular}

three thermal decompositions with the heating rates of 2,10 , and $20{ }^{\circ} \mathrm{C} \cdot \min ^{-1}$. In a summary, the sample with mixed surfactant has the lowest decomposition temperature, and then is the sample with surfactant PVA, the sample without surfactant and with surfactant PAM or Tween20 have approximate decomposition temperatures which are higher than the above two. Therefore, we concluded that the spherical samples have the lower decomposition temperature and the sheet samples will decompose at a higher temperature.

These figures also show that sample with the same morphological properties has different decomposition temperatures when the heating rate changes. The thermal decomposition process of the sample with mixed surfactant at a heating rate of $2{ }^{\circ} \mathrm{C} \cdot \mathrm{min}^{-1}$ has a peak temperature of $200.56{ }^{\circ} \mathrm{C}$, when the heating rate varies from 5,10 , to $20{ }^{\circ} \mathrm{C} \cdot \mathrm{min}^{-1}$ the peak temperature changes from $208.10,215.17$, to $222.86{ }^{\circ} \mathrm{C}$. The other four samples with different morphologies have the same performance, which was studied in the kinetic properties in detail. That is to say, as the heating rate becoming larger, the pyrolysis temperature of KDNBF with different morphologies is higher

\subsection{Non-isothermal kinetics analysis of KDNBF with different morphologies}

Kissinger's ${ }^{[24]}$ and Ozawa-Doyle' $\mathrm{s}^{[25]}$ methods were applied to study the kinetics parameters based on the exothermic peak temperatures measured from DSC curves with the heating rates of 2, 5,10 , and $20{ }^{\circ} \mathrm{C} \cdot \mathrm{min}^{-1}$. The Kissinger equation (Eq.(2)) and Ozawa-

Table 3 Reaction kinetic parameters of KDNBF with different surfactants

\begin{tabular}{|c|c|c|c|c|c|c|c|}
\hline \multirow{2}{*}{ Sample } & \multicolumn{4}{|c|}{ Kissinger } & \multicolumn{3}{|c|}{ Ozawa-Doyle } \\
\hline & $E_{\mathrm{k}} /\left(\mathrm{kJ} \cdot \mathrm{mol}^{-1}\right)$ & $\ln A$ & $r$ & $S$ & $E_{0} /\left(\mathrm{kJ} \cdot \mathrm{mol}^{-1}\right)$ & $r$ & $S$ \\
\hline a & 172.5 & 37.42 & 0.9998 & 0.03193 & 171.8 & 0.9997 & 0.01373 \\
\hline $\mathrm{b}$ & 174.5 & 37.92 & 0.9993 & 0.04229 & 173.7 & 0.9994 & 0.01821 \\
\hline c & 194.7 & 43.45 & 0.9997 & 0.03005 & 192.9 & 0.9997 & 0.01316 \\
\hline d & 178.6 & 38.98 & 0.9976 & 0.08010 & 177.6 & 0.9978 & 0.03494 \\
\hline $\mathrm{e}$ & 196.4 & 44.26 & 0.9988 & 0.05747 & 194.4 & 0.9989 & 0.02483 \\
\hline
\end{tabular}

The meanings of a-e are the same as those in Fig.l. $E_{\mathrm{k}}$ : the apparent activation energy calculated by the Kissinger's method, 
Doyle equation (Eq.(3)) are as follows. The kinetic parameters of the thermal decomposition reaction were shown in Table 3.

$$
\begin{gathered}
\frac{\mathrm{d} \ln \left(\beta / T_{\mathrm{p}}^{2}\right)}{\mathrm{d}\left(1 / T_{\mathrm{p}}\right)}=-\frac{E_{\mathrm{k}}}{R} \\
\lg \beta+\frac{0.4567 E_{\mathrm{o}}}{R T_{\mathrm{p}}}=C
\end{gathered}
$$

where $T_{\mathrm{p}}$ is the peak temperature; $R$ is the gas constant; $\beta$ is the linear heating rate; $C$ is a constant, $E_{\mathrm{k}}$ and $E_{\mathrm{o}}$ are the apparent activation energy.

The data in Table 3 show that the KDNBF with different morphologies have different reaction kinetics parameters. The sample with the most regular spherical morphology has the highest reaction activation energy with the value of $E_{\mathrm{a}}$ (the average of $E_{\mathrm{k}}$ and $E_{\mathrm{o}}$ ) is $195.4 \mathrm{~kJ} \cdot \mathrm{mol}^{-1}$, which indicates that this kind of $\mathrm{KDNBF}$ needs higher temperature to decompose and is more stable than other samples. The second higher reaction activation energy belongs to the sample with nearly spherical morphology that synthesized with the adding of surfactant PVA with the value of $E_{\mathrm{a}}$ is $193.8 \mathrm{~kJ} \cdot \mathrm{mol}^{-1}$. The samples without surfactant and with surfactant PAM or Tween20 have the similar sheet morphologies and approximate reaction activation energies. The Arrhenius equations for the exothermic process of the five samples with different morphologies can be expressed by using the calculated $E_{\mathrm{a}}$ and $\ln A$ values. The equations of the five samples of a $-\mathrm{e}$ are listed as following: $\ln k=37.42-172.2 \times 10^{3} / R T, \ln k=$ $37.92-174.10 \times 10^{3} / R T, \ln k=43.45-193.8 \times 10^{3} / R T, \ln k=38.98-$ $178.1 \times 10^{3} / R T$, and $\ln k=44.26-195.4 \times 10^{3} / R T$.

From the above results, we can conclude that the morphology has great influence on the decomposition behavior of KDNBF. The spherical sample has higher reaction activation energy than the sheet sample. The reason of this phenomenon is that the lumpish samples have many edges and corners than the spherical sample. When the sample is heated, the sheet sample will engender more hot-spots that make the decomposition of sample easier than the spherical sample.

\subsection{Thermal weight-loss process of KDNBF with different morphologies}

The thermal weight-loss process of KDNBF with different morphologies was tested by the TG analysis shown in Fig.4.

As we can see from Fig.4, there is great difference among the TG curves between the sample without surfactant and samples with various surfactants. The sample without surfactant has a rapid weight-loss process, and gets the equilibrium early at 350 ${ }^{\circ} \mathrm{C}$. The samples with surfactants have slow and stepwise weight-

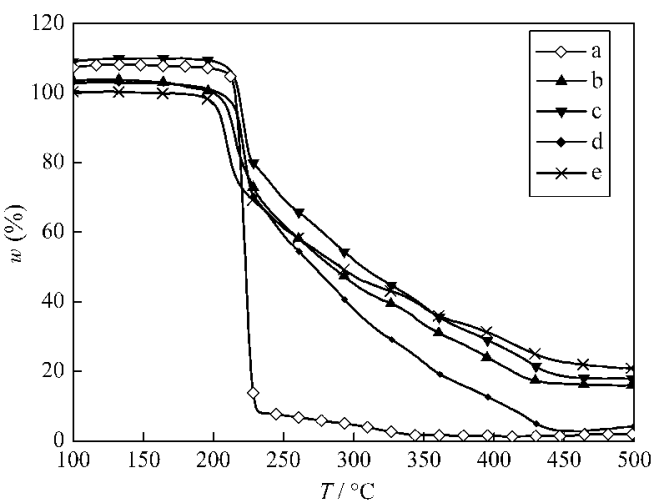

Fig.4 TG curves of KDNBF with different surfactants at a heating rate of $10{ }^{\circ} \mathrm{C} \cdot \mathrm{min}^{-1}$

The meanings of a-e are the same as those in Fig.l.

loss process. They all decomposed completely and get the equilibrium at $450-500{ }^{\circ} \mathrm{C}$. The percent of solid residue of each kind of sample is different and all less than $22 \%$. The surfactants made the weight-loss process of KDNBF with different morphologies gentler, but did not influence the result of the decomposition.

\subsection{Sensitivity test of KDNBF with different morphologies}

Friction sensitivity was tested by using a Pendulum Apparatus. The sample of $20 \mathrm{mg}$ was compressed between two steel poles with mirror surfaces at the pressure of $1.96,1.28$, and 0.64 $\mathrm{MPa}$, and then it was hit horizontally with a $1 \mathrm{~kg}$ hammer from $90^{\circ}, 70^{\circ}$, and $50^{\circ}$ angles, respectively. The test results of friction sensitivity show that samples with different morphologies all fire under the test condition of $90^{\circ}$ and $70^{\circ}$ angles. However, when hit horizontally from $50^{\circ}$ angle, the order of the firing rate of different samples is as follows: KDNBF-mixed surfactant $>\mathrm{KDNBF}-$ PVA $>$ KDNBF - PAM $>$ KDNBF - Tween20 $>$ KDNBF-no surfactant, which is coincident with the exothermic peak temperatures of different kinds of sample. The reason for this is that the spherical sample has regular morphology and equal friction force in each direction.

Impact sensitivity was determined by using a Fall Hammer Apparatus. The sample of $20 \mathrm{mg}$ was compacted to a copper cap under the press of $39.2 \mathrm{MPa}$ and then hit by $800 \mathrm{~g}$ hammer with a designed apparatus. The results reveal that the spherical sample also has the highest value. Meanwhile, the order with different morphologies is consistent with the conclusion of friction

\begin{tabular}{|c|c|c|c|c|c|c|c|}
\hline \multirow{2}{*}{ Sample } & \multicolumn{3}{|c|}{ Friction sensitivity } & \multicolumn{2}{|c|}{ Impact sensitivity } & \multicolumn{2}{|c|}{ Flame sensitivity } \\
\hline & $90^{\circ}, 1.96 \mathrm{MPa}$ & $70^{\circ}, 1.28 \mathrm{MPa}$ & $50^{\circ}, 0.64 \mathrm{MPa}$ & $H_{50} / \mathrm{cm}$ & $S / \mathrm{cm}$ & $H_{50} / \mathrm{cm}$ & $S / \mathrm{cm}$ \\
\hline $\mathrm{a}$ & $100 \%$ & $100 \%$ & $30 \%$ & 21.92 & 1.79 & 50.70 & 5.49 \\
\hline $\mathrm{b}$ & $100 \%$ & $100 \%$ & $40 \%$ & 21.42 & 0.98 & 48.41 & 8.13 \\
\hline $\mathrm{c}$ & $100 \%$ & $100 \%$ & $50 \%$ & 20.75 & 0.62 & 47.59 & 0.48 \\
\hline $\mathrm{d}$ & $100 \%$ & $100 \%$ & $35 \%$ & 23.83 & 1.49 & 52.80 & 4.92 \\
\hline $\mathrm{e}$ & $100 \%$ & $100 \%$ & $55 \%$ & 20.00 & 0.72 & 49.30 & 6.14 \\
\hline
\end{tabular}

Table 4 Sensitivity results of KDNBF with different surfactants

The meanings of a-e are the same as those in Fig.1. $H_{50}$ : the height for $50 \%$ probability of ignition; $S$ : standard deviation 
sensitivity, expect for the reversal order of KDNBF with Tween 20 and KDNBF with no surfactant.

Flame sensitivity was conducted according to the standard method $^{[26]}$. The sample of $20 \mathrm{mg}$ was compacted to a copper cap under the press of $39.2 \mathrm{MPa}$ and ignited by standard black powder pellet right above the sample. The order of the $50 \%$ firing height of different samples is KDNBF-Tween20 $>$ KDNBF-no surfactant $>$ KDNBF-mixed surfactant $>$ KDNBF-PAM $>$ KDNBFPVA. The results reveal that the lumpish sample has a moderate flame sensitivity.

The sensitivity test results of KDNBF with different surfactants are listed in Table 4. In conclusion, comparing with the lumpish samples (with surfactant PAM or Tween20 or without surfactant), the spherical samples (with mixed surfactant or surfactant PVA) have higher friction and impact sensitivities and moderate flame sensitivity. However, it is more stable than RbDNBF ${ }^{[2]}$ and $\mathrm{CsDNBF}^{[28]}$. The results of sensitivity test are related with the molecular structure and thermal stability of the compound.

\section{Conclusions}

KDNBF with different morphologies were obtained by adding different surfactants into the reaction system in the process of

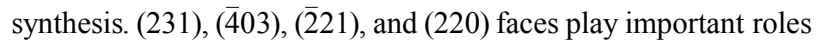
during the crystal growth process. According to the thermal and kinetic analyses, we find that the spherical sample has lower decomposition temperature and higher reaction activation energy than the sheet sample. The surfactants make the weight-loss process of KDNBF with different morphologies gentler, but do not influence the result of the decomposition. Sensitivity studies indicate that the friction and impact sensitivities of the spherical sample are higher than the lumpish sample, which is of significance interest for ammunition application.

\section{References}

1 Michael, S.; Magdy, B.; John, F.; Michael, W.; William, S.; Richard, G. Proceedings of the international pyrotechnics seminar. Salisbury, Australia: Defence Science \& Technology Organisation, Pyrotechnics Group, 2004: 729-734

2 Gil'manov, R. Z.; Falyakhov, I. F.; Sudakova, A. I.; Malikov, A. A.; Kislin, M. A.; Kilina, A. M.; Khusainov, R. M. Impact detonation compositions as primers for use in detonating caps for small arms ammunition cartridges: Russian, 2317966[P]. 2008-0207

3 Jones, D. E. G.; Lightfoot, P. D.; Fouchard, R. C.; Kwok, Q.; Turcotte, A. M.; Ridley, W. Thermochim. Acta, 2002, 384: 57

4 Jones, D. E. G.; Feng, H. T.; Fouchard, R. C. Proceedings of the international pyrotechnics seminar. Chicago: IIT Research Institute, 1999: 195-202

5 Shinde, P. D.; Mehilal; Salunke, R. B.; Agrawal, J. Propellants Explos. Pyrotech., 2003, 28: 77

6 Löbbecke, S.; Keicher, K.; Krause, H.; Pfeil, A. Solid State Ion., 1997, 101: 945
7 Jones, D. E. G.; Feng, H. T.; Fouchard, R. C. J. Therm. Anal. Calorim., 2000, 60: 917

8 Gaughran, R. J.; Picard, J. P.; Kaufman, J. V. R. J. Am. Chem. Soc., 1954, 76: 2233

9 Norris, W. P.; Osmundsen, L. J. Org. Chem., 1965, 30: 2407

10 Piechowics, T. Potassium of 4,6-dinitrobenzofuroxan-a useful initiating explosive: France, 1579799[P], 1968-04-05

11 Bjerke, R. K.; Ward, J. P.; Ells, D. O.; Kees, K. P. Improved primer composition: US, 4963201[P], 1990-10-16

12 Duguet, J. R. Priming charges with annular percussion and process for its manufacture: US, 5353707[P], 1994-10-11

13 Carter, G. B. Primer compositions containing dinitrobenzofuroxan compounds: US, 5538569[P], 1996-07-23

14 Rinaldi, S.; Talini, F. Printing mixture containing no toxic materials, and cartridge percussion primer employing such a mixture: US, 5672219[P], 1997-09-30

15 Fogelzang, A. E.; Korolev, V. P.; Egorshev, V. Y.; Kolesov, V. I.; Pochukaev, V. D.; Baskakov, Y. M.; Tokarev, A. S.; Bibnev, N. M.; Hovanskov, V. N.; Evdokimova, I. F.; Voronin, Y. P. Pyrotechnical percussion combustion composition for small arms ammunition primers: US, 6165294[P], 2000-12-26

16 Brede, U.; Bley, U. Use of a microjet reactor for the production of initiating explosive: US, 0188874[P], 2005-02-09

17 Lur'e, B. A.; Sinditskii, V. P.; Smirnov, S. P. Fiz. Goreniya Vzryva, 2003, 39: 55

18 Li, Y. F.; Zhang, T. L.; Zhang, J. G. Chin. J. Energ. Mater., 2004, 12: 203 [李玉峰, 张同来, 张建国. 含能材料, 2004, 12: 203]

19 Mehilal, A. K.; Sikder, P. S.; Sikder, N. J. Hazard. Mater., 2002, 90: 221

20 McGuchan, R. Improvement in primary explosive compositions and their manufacture[C]//Franklin Research Center, a division of the Franklin Institute, Proceedings of the 10th Symposium on Explosives and Pyrotechnics, Symposium on Explosives and Pyrotechnics, San Francisco, California, February 14-16, 1979, Philadelphia, Pa: Franklin Research Center, 1979: 1-12

21 Ren, Z. Q.; Yu, T. Y.; Xu, B. Y. Chin. J. Energ. Mater., 1995, 4: 7 [任志奇, 于天义, 许碧英. 含能材料, 1995, 4: 7]

22 Coulouarn, C. Synthesis of potassium dinitrobenzofuroxan: EP, 1627872[P], 2006

23 Li, Y. F.; Zhang, T. L.; Zhang, J. G.; Miao, Y. L. Chin. J. Explos. Propellants, 2003, 26: 53 [李玉峰, 张同来, 张建国, 苗艳玲. 火 炸药学报, 2003, 26: 53]

24 Kissinger, H. E. Anal. Chem., 1957, 29: 1702

25 Ozawa, T. Bull. Chem. Soc. Jpn., 1965, 38: 188

26 Wang, S. Z.; Zhang, T. L.; Sun, Y. H.; Zhang, J. G. Chin. J. Energ. Mater., 2005, 13: 53 [王绍宗, 张同来, 孙远华, 张建国. 含能材 料, 2005, 13: 53]

27 Liu, Z. T.; Lao, Y. L. Experiment of primary explosive. Beijing: Beijing Institute of Technology Publishing Company, 1995: 238-250

28 Wang, S. Z.; Zhang, T. L.; Yang, L.; Zhang, J. G.; Sun, Y. H. Propellants Explos. Pyrotech., 2007, 32: 16 